\title{
Who uses mobile phone while driving for food delivery? : The role of personality, risk perception, and driving self-efficacy
}

\section{Abstract}

\section{Introduction}

The existing literature on mobile phone use while driving (MPUWD) mainly targets the participants from general population and the young adults, however, few studies pay attention to this form of distracted driving with samples in professional contexts. The present study aims to bridge the gap by identifying the extent of and the motives behind making use of mobile phone while driving for food dispatch among deliveryman.

\section{Method}

The snowball sampling was used to collect the data $(\mathrm{N}=317)$ through a self-reported questionnaire, including demographics, personality traits, risk perception, driving self-efficacy and mobile phone use while driving.

\section{Results}

Descriptive analysis for the assessed MPUWD behaviors showed that $96.3 \%(\mathrm{~N}=315)$ of food deliveryman undertook the MPUWD behaviors though disproportionate distribution among these behaviors existed. Structural equation modeling analysis displayed that psychoticism and driving self-efficacy directly predicted the MPUWD behaviors. The mediating role of driving self-efficacy 
was verified with the findings that driving self-efficacy completely mediated the relationships that between risk perception and MPUWD behaviors and that between extraversion and MPUWD behaviors, as well as partially mediated the correlation between psychoticism and MPUWD behaviors.

\section{Conclusions}

The present study confirms the prevalence of MPUWD behaviors among food deliveryman. The SEM estimates and bootstrap estimates suggest that personality traits and perceived risk perception per se display limited predicting utility to MPUWD behaviors among food deliveryman whereas driving self-efficacy and the proposed predictors together well illustrate the assessed MPUWD behaviors among food deliveryman.

\section{Practical Applications}

These findings imply that developing and implementing intervention efforts in a concerted way would curb these behaviors effectively.

Keywords: Mobile phone use while driving, Personality traits, Risk perception, Driving self-efficacy, Structural equation modeling

\section{Introduction}

Mobile phone use while driving (MPUWD) is a pressing and prevalent safety concern around the world(WHO, 2011). Mobile phones are considered to be a severe form of distraction as it can deplete the driver's visual, physical and cognitive resources(Ige, Banstola, \& Pilkington, 2016). Distracted driving is described as undertaking secondary activities that could divert a driver's attention away from the primary task of operating a vehicle safely (Lee, Young, \& Regan, 2008; 
Regan, Hallett, \& Gordon, 2011). Distractions triggered by mobile phones can be manual(e.g. taking hands off the wheel to answer an incoming call), visual (e.g. looking away from the road to check the message), cognitive (e.g. diverting attention away from perception of the road) and auditory (e.g. conversing on the mobile phone) (Lipovac, Đerić, Tešić, Andrić, \& Marić, 2017).

Existing studies confirm that engaging in mobile phones tasks while driving, especially when visual attention is diverted, is an increasing contributor to accident risks and vehicle crashes (Simmons, Hicks, \& Caird, 2016; Wilson \& Stimpson, 2010). Epidemiological studies suggest that people who engage in mobile phone tasks frequently while driving have a high likelihood of experiencing an accident (Laberge-Nadeau et al., 2003; McEvoy, Stevenson, \& Woodward, 2006; Seo \& Torabi, 2004). For instance, Elvik (2011) revealed that the odds of accident involvement for those engage in mobile use while driving were at least 3-fold higher than those unengaged in mobile use. Redelmeier and Tibshirani (1997) recorded that collision risk for mobile phone users ranged from 3 to 6.5 times higher than that of the nonusers. Furthermore, extant studies document that MPUWD incur detrimental effects on driving performance, including reaction time (Bellinger, Budde, Machida, Richardson, \& Berg, 2009; Choudhary \& Velaga, 2017; Haque \& Washington, 2014), visual information processing (Briggs, Hole, \& Land, 2011; Strayer, Drews, \& Johnston, 2003), lane-keeping (Drews, Pasupathi, \& Strayer, 2008; He, McCarley, \& Kramer, 2014), headway (Lesch \& Hancock, 2004) and vehicle speed (Rakauskas, Gugerty, \& Ward, 2004; Törnros \& Bolling, 2005).

\section{literature review}

Using a hand-held mobile phone for calling or texting while driving is legally prohibited in 
Australia(Waddell \& Wiener, 2014), China(Shi, Xiao, \& Atchley, 2016), U.S. states (McCartt \& Geary, 2004) and many other countries worldwide(Cellular News, 2019). Though legally permitted, hand-free mobile phone use while driving does not have any safety advantages over hand-held mobile phone use(Törnros \& Bolling, 2005). However, despite successive deterrence-based efforts and educational campaigns, studies have documented little impacts of these interventions in reducing mobile phone uses (either hands-free or hand-held) while driving (H.-S. Kim, 2018; McCartt, Hellinga, Strouse, \& Farmer, 2010; Rozario, Lewis, \& White, 2010). Given the continued prevalence of mobile phone use while driving, having a good understanding of the psychosocial factors of MPUWD is of importance in informing and improving intervention strategies (Braitman \& Braitman, 2017; M. Sullman, Hill, \& Stephens, 2018). However, most studies on the psychological and social underpinnings of MPUWD tend to concentrate on distinguishing drivers who may undertake mobile phone tasks from those who may not while driving (Brusque \& Alauzet, 2008; Hill, Sullman, \& Stephens, 2019). Consequently, more research is needed to understand the psychosocial antecedents of mobile phone use while driving.

The theory of planned behavior (TPB) has been widely used to explain human social behavior with attitude, subjective norm and perceived behavioral control (PBC) serving as predictors. Attitude refers to the individuals' positive of negative evaluations about performing a given behavior. Subjective norm is defined as perceived social pressure from important referents to engage or not engage the behavior. $\mathrm{PBC}$ refers to the perceived ease or difficulty in performing the behavior (Ajzen, 1991). A growing body of literature has confirmed the utility of the theory of planned behavior (TPB) in explaining the intentions to engage (Gauld, Lewis, White, Fleiter, \& Watson, 2017; Tian \& Robinson, 2017; Waddell \& Wiener, 2014; Walsh, White, Hyde, \& Watson, 
2008; R. Zhou, Wu, Rau, \& Zhang, 2009) and actual engagements(M. J. Sullman, Przepiorka, Prat, \& Blachnio, 2018; K. M. White, Hyde, Walsh, \& Watson, 2010) with mobile phones while driving. Most of the above research extended the TPB with additional variables to account for additional unexplained variances (Armitage \& Conner, 2001). Research findings suggest the TPB variables' effects on MPUWD vary from one study to another, and generally, attitudes towards mobile phone use and perceived behavioral control (PBC) appear to be the most influential predictors, whereas subjective norm emerges as a weaker predictor (Gauld, Lewis, \& White, 2014; Tian \& Robinson, 2017). Moreover, some studies indicate that the predictive power of TPB variables on MPUWD behavior appears to be context-dependent (Przepiorka, Błachnio, \& Sullman, 2018; M. Sullman et al., 2018; Walsh et al., 2008). For example, scholars have found that PBC was a positive and significant predictor of texting when not in a hurry while a negative and significant one when running late (M. Sullman et al., 2018). Notably, under the extended TPB framework past behavior (Nemme \& White, 2010; Tian \& Robinson, 2017) and moral norm (or descriptive norm) (Nemme \& White, 2010; Waddell \& Wiener, 2014), both emerge as significant predictors of MPUWD behavior. Given the criticism and limitations of TPB (Brown, George, \& Rickwood, 2019), the present study tries to unveil the motives behind MPUWD outside this theoretical framework.

Indeed, researchers have attempted to explore the psychosocial antecedents of MPUWD beyond the TPB framework by considering potentially relevant variables. Given prior studies have laid the theoretical foundations that certain personality traits can predict generalized mobile phone use (Bianchi \& Phillips, 2005; Butt \& Phillips, 2008) and unsafe driving behaviors (Groeger \& Rothengatter, 1998), researchers have started to focus on specific personality attributes that could account for the extra variance in MPUWD. A recent study found participants with a higher level of 
impulsivity were more likely to text (Hayashi, Rivera, Modico, Foreman, \& Wirth, 2017), but the finding from another study discovered this result only applied for men's texting behavior (Struckman-Johnson, Gaster, Struckman-Johnson, Johnson, \& May-Shinagle, 2015). Some studies revealed that sensation-seeking is significantly and positively related to interactions to mobile phone tasks while driving (H.-Y. W. Chen \& Donmez, 2016; Rupp, Gentzler, \& Smither, 2016). Interestingly, the Big Five personality constructs appear to be valid predictors of distracted driving behaviors when using a mobile phone, although the strength of these relationships vary from teens to older adults (Parr et al., 2016). By introducing smartphone addiction as the potential mediating variable, Kita and Luria (2018) displayed openness to experience decreased while extraversion and neuroticism increased the likelihood of smartphone use while driving, but the moderation effect of smartphone addiction only worked on the relationship between neuroticism and smartphone use while driving. Sween, Ceschi, Tommasi, Sartori, and Weller (2017) recorded risk perceptions acted as a mediating role on the relationships between four HEXACO dimensions (honesty/humility, conscientiousness, openness and emotionality) and the self-reported frequency of mobile phone use while driving. These studies confirm that certain personality traits significantly correlate to MPUWD behaviors, and that there may be some variables moderate the effects of personality traits on MPUWD behaviors.

Considering the potential for detrimental consequences and the perceived risks incurred by MPUWD (Ismeik, Al-Kaisy, \& Al-Ansari, 2015; Nurullah, Thomas, \& Vakilian, 2013), it is meaningful to check whether risk perception would translate into the possibility of engaging with these activities. With the risk perception gauged with crash risk and risk of apprehension, studies found only crash risk lessen the behavioral intention of texting (Brown et al., 2019; Przepiorka et al., 
2018) while Walsh et al. (2008) displayed apprehension risk enhance the intention of texting when on wheel. In contrast to these findings, M. Sullman et al. (2018) revealed there was no relationship between both types of perceived risks and texting and calling while driving. Likewise, we cannot come to the conclusion that the risk perception measured with subjective ratings of specific activities would contribute to engagements with mobile phone while driving given the complicated results (Hallett, Lambert, \& Regan, 2011; Ismeik et al., 2015). A recent study argues that the choice to use mobile phone while driving might shape the perceived risk (Atchley, Atwood, \& Boulton, 2011). Despite this, the inference that risk perceptions may indirectly lead to actual interactions to mobile phone while driving (Przepiorka et al., 2018) and the finding that anticipated regret fully mediates the association between perceived risk and intention to text-sending (Brown et al., 2019) suggest examining the indirect effect of risk perception on behavioral intentions or activities of MPUWD is a worthy future research direction.

\section{The present study: context and hypotheses}

Although works on psychosocial aspects of mobile phone use while driving are burgeoning, their targeted participants are typically samples drawn from general population and the young adults. To date, to our knowledge, there has been no work exploring social and psychological predictors of MPUWD with samples from professional drivers (e.g. taxi drivers, bus drivers) or mobile professionals who drive to pursue their job (e.g. deliveryman), except by Bruyas and Evennou (2018) who showed that motives behind MPUWD in professional contexts varied across pattern of phone use and occupation, and Claveria (2018) who found that driver characteristic, work characteristics, temporal characteristics, driving behavior and management characteristics were 
valid predictors of cell phone use among truckers at the wheel.

The likelihood of higher interaction with mobile phone use and the greater exposure to risks while driving in professional contexts (Brusque \& Alauzet, 2008; Troglauer, Hels, \& Christens, 2006) means that greater understanding of MPUWD among workers is important. For instance, Troglauer and colleagues (2006) studied MPUWD among professional truck drivers. These researchers identified a marked discrepancy in drivers' reported use and perceptions of other drivers' use of mobile phones. For instance, although 99\% of truck drivers reported using a mobile phone while driving at least once, only $6 \%$ reported that such use had contributed to a dangerous driving situation. This result is despite a perception among $66 \%$ of these drivers that others' MPUWD contributed to a dangerous situation. In other words, professional drivers, at least in commercial trucking, regularly use mobile phones and do not believe they contribute to dangerous situations, despite transportation experiencing markedly high accident rates compared to other industries.

Adding complication to the relationship between MPUWD and occupational factors, although Brusque and Alauzet (2008) found that occupational status did not predict meaningfully MPUWD, they did suggest that phone use may interact with experience, meaning that MPUWD may affect accident outcome less intensely for experienced versus inexperienced drivers. This result is especially relevant to the app-based industry, where services such as Uber and Lyft have attracted thousands of inexperienced commercial drivers, and mobile-phone-based technologies essentially mediate all interactions between the company, the driver, and the passenger (Gloss, McGregor \& Brown, 2016). Ride-sharing platforms have also reportedly been experimenting with app-based techniques to entice driver interactions, including mini-games, non-cash rewards, and engaging 
graphics (Scheiber, 2017). This combination of inexperience with increased phone-driven interactions may create a higher risk situation for working drivers. Therefore, the primary aim of this study is to examine the motives of mobile phone use while driving, with samples from food deliverymen, an emerging occupational group in China.

Mobile technology advances and the changing lifestyle/living standards are spurring the explosive growth of $\mathrm{O} 2 \mathrm{O}$ (Online to Offline) food delivery industry in China. The size of the industry’s market increased from US\$3.4 billion in 2011 to US\$36.3 billion in 2018 (Group, 2017) and the registered users rose from 114 million in 2015 to 397 million in 2018 (CNNIC, 2019). The take-off of the $\mathrm{O} 2 \mathrm{O}$ food delivery industry is underpinned by the offline delivery service of the food deliverymen who rush around the streets to dispatch the ordered food at any time and under any weather conditions. At present, nearly 7 million people are engaged in food delivery in China (Xinhua News Agency, 2017). Electric bike and installation of the platforms' applications on smartphone are necessary equipment in the process of delivering food. However, food deliverymen are working around complicated environments with the addition of physical demands, quality service and time-consuming nature of the sector. Delivery drivers could resort to risky driving practices, such as using a cell phone, driving through red lights to maximize their earnings and avoid possible negative comments from consumers (Shepherd, 2017; Talaat \& Yuan, 2017; V. Zhou, 2018). Indeed, the influx of food deliverymen is fuelling concerns about road safety evidenced by the statistics that food delivery bikes were involved in over 3,000 accidents in the first half of 2017 in Nanjing (a city located in east China with a population of 8.34 million people) (Economist, 2017) and 76 injuries and deaths occurred among food deliveryman in the first half of 2017 in Shanghai (Shepherd, 2017). 
MPUWD is a prevalent phenomenon among food deliveryman, which mainly stems from their working environment, including interacting with their platform's application and communicating with consumers. Mobile phones are an indispensable device for food deliveryman, on which a custom application from the platforms (e.g. Ele.me, Meituan) is installed to connect the online and offline system to help deliveryman to check the assigned orders, order information, and sometimes compete to get the order. There is also a built-in positioning tool within the deliveryman's application with the aim to locate and direct the destination. The prevalence of MPUWD among food deliveryman can be evidenced by an increasing number of relevant news coverages, though there are no available official statistics. For example, it has recently been reported that 11 people were caught for their engaging in mobile phone activities while driving in only in one hour in a special enforcement action undertaken in Jinjiang May 2018. Nine of the infringements issued were to food deliverymen (Jinjiang Economist, 2018).

Regulation on the Implementation of the Road Traffic Safety Law of the People's Republic of China prohibits handheld mobile phone uses while driving. Motor vehicle drivers violating this ban can be fined up to 200 yuan $(\$ 28)$ and lose 2 points on their driver's license. Non-motor vehicle drivers violating this ban will be fined 20 yuan(\$3). However, continued enforcements practices among Chinese cities appear to be less effective in reducing deliverymen's uses of mobile phone while delivering foods. Statistics from Nanjing Traffic Management Bureau shows that there are 4503 proven traffic violations by food deliverymen in the second half of 2018 and that MPUWD is a common type of violations. Since 2019, in addition to fines, Nanjing traffic police have tried to organize special education campaigns targeted at food deliverymen violated twice. Nanjing Traffic Management Bureau also collaborates with deliverymen's employers to prohibit the entry of 
recidivist into food delivery(Wang, 2019). However, these efforts are still lackluster in changing their uses of mobile phone while delivering foods. Therefore, identifying who is more likely to use mobile phone among food deliverymen could be highly useful to develop effective interventions with the aim to reduce this kind of risky driving behavior.

The present study aims to address two objectives. The first objective is to identify the current state of mobile phone use while food deliverymen are distributing the prepared food. The second one is to examine the effects of Eysenck personality traits and risk perception on frequency of MPUWD as mediated by driving self-efficacy. Driving self-efficacy is introduced as a possible mediating factor on the influences of personality traits and risk perception. Grounded in generalized self-efficacy (Bandura, 1997), driving self-efficacy is a construct employed to gauge participants' perceived competence pertaining to the performance of specific tasks while driving (Sundström, 2008). As summarized above, under the PTB framework, PBC was an influential modifier to mobile phone use while driving. Conceptually, PBC is closely related to driving self-efficacy(Wohleber \& Matthews, 2016). Thus, we predict that the higher perceived driving self-efficacy by food deliveryman corresponds to a more frequent mobile phone use while driving for their work, which is a core hypothesis to our hypothesized structural model. Specifically, the following hypotheses are to be tested.

Existing studies have shown that respondents interviewed perceive using mobile phone while driving as highly risky behaviors(Ismeik et al., 2015; Nurullah et al., 2013).However, some studies found that the corresponding perceived risks did not directly reduce both behavioral intentions and activities of mobile phone use while driving (Nelson, Atchley, \& Little, 2009; Rupp et al., 2016; M. Sullman et al., 2018). Underpinned by this research finding, we predict: 
H1: There is dissociation between risk perception and mobile phone use for food deliverymen while driving for their work.

Comparative utility and social expectation are two well-acknowledged interpretations in answering why drivers interact with mobile phones though they are cognizant of the associated risks (Ismeik et al., 2015). Notably, a recent study recorded, though perceiving associated risks, those who have a high level of illusory control or ability to compensate for phone-related distractions tend to frequently engage in this activity, providing an another promising and intriguing research direction (Schlehofer et al., 2010). Accordingly, we predict:

H2: Driving self-efficacy would fully mediate the relationship between risk perception and the frequency of MPUWD among food deliveryman.

Investigating the role of personality traits on unsafe driving behavior has been one of the central topics in road safety research. However, questions concerning the generalizability of prior results into the narrow unsafe driving behaviors - mobile phone use while driving-are less clear. To replicate previous research findings pertaining to the effects of personality traits on unsafe driving behavior (Furnham \& Saipe, 1993; Renner \& Anderle, 2000; Tao, Zhang, \& Qu, 2017), we predict:

H3-H5: Greater extraversion, neuroticism and psychoticism would be associated with higher frequency of MPUWD among food deliverymen.

Moreover, research has documented that biased self-efficacy mediates the relationship between certain personality trait and specific risky driving behavior (González-Iglesias, Gómez-Fraguela, \& Luengo, 2014). We are convinced that this may also be reasonable for mobile phone use while driving. Hence, we predict: 
H6-H8: Driving self-efficacy will mediate the relationships between extraversion, neuroticism and psychoticism on one hand and mobile phone use while driving among food deliveryman on the other.

\section{Methods}

\section{Participants and procedures}

The study was part of the project 'risky driving behaviors among food deliveryman', dedicating to inform effective interventions in reducing these behaviors. A pilot survey was administrated with 18 experienced food deliveryman aimed at testing the questionnaire's length and focused on the comprehensibility of the instruments. Incorporating feedback, the questionnaire was revised by rewording a few items to make them more understandable, adjusting the scales' order to enhance the food deliverymen's willingness to participate, and deleting the social desirability scale from The Eysenck Personality Questionnaire.

The formal survey lasted three months, from July 2018 to September 2018. Participants were recruited by snowball sampling of food deliveryman encountered in prosperous urban business blocks from Xuzhou and Nanjing, two municipalities located in eastern China. Three actions were taken to maximize the quality of the responses. First, the respondents were informed that their responses would be confidential. Second, each respondent was assisted by a trained research assistant (master student or doctoral student) to assist them with completing the questionnaire. Third, generally, the questionnaire distribution happened around 10 a.m. after their morning meeting at the gathering points, when the food deliveryman had not yet begun their work and so they were very 
supportive of the survey.

In total, 334 participants voluntarily responded to the paper-pencil self-reported survey. Among them, 17 responses were discarded from the data analysis due to several considerations. 8 cases for the missing values in personality traits (Maij-de Meij, Kelderman, \& van der Flier, 2008), 8 cases for the unengaged response (selecting the same answer for group of items) as values of the variance were equal to zero (Gaskin, 2017)and 1 case with more than 5\% missing values (Hair, Black, Babin, \& Anderson, 2014). Thus, 327 samples were employed for the subsequent analysis. The few missing values for some variables in the remaining 327 samples, all with no more than 5\% missing, were replaced with the median for interval variables and the mean with continuous variables.

\section{Instruments}

A standard questionnaire was formulated based on the previous studies and available instruments by translating into Chinese if necessary and transforming items to be specific to mobile phone use while driving on e-bikes. The back-translation procedure was performed by two experienced bilingual translators to guarantee the accuracy and clarity of the Chinese items. An associate professor who excelled in questionnaire design and five graduate students that once worked as research assistant on food safety issues in the $\mathrm{O} 2 \mathrm{O}$ food delivery industry were consulted to ensure the quality of the questionnaire. All the following instruments were measured on a 6-point Likert scale (1="strongly disagree" or "never" to $6=$ "strongly agree" or "always"), unless otherwise mentioned.

\section{Demographics}

A demographic information inventory was developed to obtain respondents' basic information 
(e.g. gender, age, and education), working information (e.g. length of working, working income, the platform they worked for) and the number of traffic tickets received and accidents involved while working. Gender, education and the registered platform were operationalized as categorical variables, and the remaining were continuous variable.

\section{Mobile phone use while driving}

Following previous work (Nurullah et al., 2013; Shi et al., 2016), an inventory scale was forwarded to the participants to gauge the frequency of mobile phone use by asking "In the previous week, how often did you engage in the following behaviors when driving for delivering food?". These specific behaviors included: 1) initiated a call, 2) answered a call, 3) checked the assigned order or competed for the order via the food delivery apps, 4) used the positioning device built-in the food delivery apps, 5) chatted via WeChat, 6) browsed WeChat's Moments, and 7) read the pop-ups from other apps.

\section{Driving self-efficacy}

Considering the debate between generalized self-efficacy and specific self-efficacy(S. Kim, Mone, \& Kim, 2008), this study captured self-efficacy in the driving context. Following Tronsmoen (2008) practice, driving self-efficacy in this study was measured with a 14-item scale, seven items for generalized self-efficacy and specific self-efficacy respectively, indicating the belief in their ability to succeed in certain driving occasions. The items for generalized self-efficacy were modified from the Adelaide Driving Self Efficacy Scale (ADSES) (George, Clark, \& Crotty, 2007), which has been increasingly employed in predicting risky driving behaviors (Malhotra, Charlton, Starkey, \& Masters, 2018; McNally \& Bradley, 2014a, 2014b; Rike, Johansen, Ulleberg, Lundqvist, \& Schanke, 2015) (e.g., "Driving in your local area"). To assess the respondents' confidence in their 
ability to drive on the wheel when committing the specific phone-related activities (e.g. initiate a call, chat via WeChat), the items for the specific self-efficacy were adapted from a subscale of perceived self-efficacy by Taubman-Ben-Ari, Mikulincer, and Iram (2004) .

\section{MPUWD risk perception}

A 16-item MPUWD risk perception scale was previously developed to assess the associated risk attitudes to MPUWD (Weller, Shackleford, Dieckmann, \& Slovic, 2013), which had been modified to investigate the correlation between MPUWD and its corresponding risk perceptions (Mirman, Durbin, Lee, \& Seifert, 2017; Sween et al., 2017). Respondents were asked to complete a modified version of this scale to indicate their perceived risks by performing mobile phone tasks when driving for food delivery (e.g., "Browsing WeChat's Moments while driving takes a person's eyes off the road for too long.").

\section{Personality traits}

Personality traits were gauged with the Revised Eysenck Personality Questionnaire-Short Scale for Chinese (EPQ-RSC) (Qian, Wu, Zhu, \& Zhang, 2000), which consisted of four 12-item subscales: neuroticism $(\alpha=.77-.78)$, extraversion $(\alpha=.74-.75)$, psychoticism $(\alpha=.54-.60)$, and lie ( $\alpha=.74-.75)$. Each item was rated on a dichotomous (yes/ no) format. The EPQ-RSC recently has been shown to be a valid predictor of risky driving behaviors among Chinese drivers (Tao et al., 2017). Three subscales neuroticism (e.g., “Are you an irritable person?”), extraversion (e.g., “Are you rather lively?") and psychoticism (e.g., "Do you enjoy co-operating with others?") were forwarded to the respondents in current study. Neuroticism refers to dispositions of people tend to be emotional instability or overreactivity under negative emotions. Extraversion refers to the tendency of people prone to be outgoing, active, exciting, and sociable. Psychoticism embodies a 
composite of traits, such as ego-centrism, impulsivity, and lack of sympathy.

\section{Data analyses}

Structural equation modeling (SEM) utilizing Amos 23 was employed to explore the direct and indirect effects of assessed variables on mobile phone use while driving for food dispatching among deliverymen. SEM has a clear advantage in modeling and analyzing simultaneously a theoretical structure with latent variable and observed variables with the consideration of measurement errors. This analyzing approach has been widely applied in the area of driving behaviors (Mallia, Lazuras, Violani, \& Lucidi, 2015; Mohamed \& Bromfield, 2017; Tao et al., 2017)and also distracted driving (Atchley et al., 2011; H.-Y. W. Chen \& Donmez, 2016; Nelson et al., 2009; Sween et al., 2017).

Consistent with the procedures outlined by (Falco, Piccirelli, Girardi, Dal Corso, \& Nicola, 2013; Kline, 2011), three sets of exploratory factor analysis (EFA) and confirmatory factor analyses (CFA) were conducted to test the modified instruments' model fits. When these measurement models display well, we then turn to the examination of the hypothesized structural model. In this study, the goodness-of-fit indices used for assessing model fits includes the ratio of $\chi 2$ to degrees of freedom $(\chi 2 / \mathrm{df}<3)$, root mean square error of approximation $(\mathrm{RMSEA}<0.06$, and RMSEA $<0.08$ is considered acceptable), the goodness-of-fit index (GFI $\geq 0.90$ ), the adjusted goodness-of-fit index (AGFI $\geq 0.80)$, the normed fit index (NFI $\geq 0.90)$, the comparative fit index $(\mathrm{CFI} \geq 0.90)(\mathrm{Hu} \&$ Bentler, 1999; Kline, 2011). The indirect effects in the hypothesized structural model were estimated by the bootstrapped approach with 2,000 bootstrap samples (Albuquerque, de Lima, Matos, \& Figueiredo, 2013; Kline, 2011). 


\section{Results}

\section{Demographic profile of the respondents}

Among the respondents, 94.5\% $(\mathrm{N}=309)$ were male and $5.5 \%(\mathrm{~N}=18)$ were female. Respondents were typically between the ages of $18-50(\mathrm{M}=28.69, \mathrm{SD}=6.43)$, however the majority $(86.9 \%, \mathrm{~N}=284)$ of the respondents were aged less than 35 years. About $2.1 \%(\mathrm{~N}=7)$ of the respondents completed elementary education, $80.8 \%(\mathrm{~N}=264)$ were high school or vocational graduates, $17.1 \%(\mathrm{~N}=56)$ held an undergraduate degree or master's degree. On average, the respondents had a working experience of 8.72 months $(\mathrm{SD}=9.27)$, ranging from 1 month to 48 months. The average monthly income was 5741.23 RMB, and around 50\% of them reported the monthly income was above 5000 RMB. Respondents had experienced an average of $0.42(\mathrm{SD}=$ 1.02) accidents when delivering food in the past half a year, with the majority of them $(75.8 \%)$ answering no accident. Likewise, respondents had been received on average $0.50(\mathrm{SD}=1.21)$ tickets for traffic offences, $71.9 \%$ of the respondents reported they didn't receive an infringement ticket.

\section{Mobile phone use while driving among food deliveryman}

Overall, the majority of the respondents $96.3 \%(\mathrm{~N}=315)$, reported that they at least demonstrated one of the seven assessed activities while driving for food dispatch. However, the distribution of the specific activities was considerable uneven on the Likert scale (Table 1). Specifically, the most frequent MPUWD behaviors, undertook sometimes or more, were employing the positioning device built-in the food delivery apps $(75.8 \%)$, checking the assigned order or 
competing for the order via the food delivery apps (65.1\%), initiating a call (62.4\%), and answering a call $(63 \%)$. These high percentages corroborate that custom apps from the platform and the mobile phone both were the indispensable instruments for those worked for this profession. Comparatively, chatting via WeChat (36.1\%), browsing WeChat's Moments (26\%), and reading the pop-ups from other apps (18\%), performed sometimes or more, were less frequent MPUWD behaviors.

Table 1 Descriptive statistics of mobile phone use while driving for food delivery $(\mathrm{N}=327)$

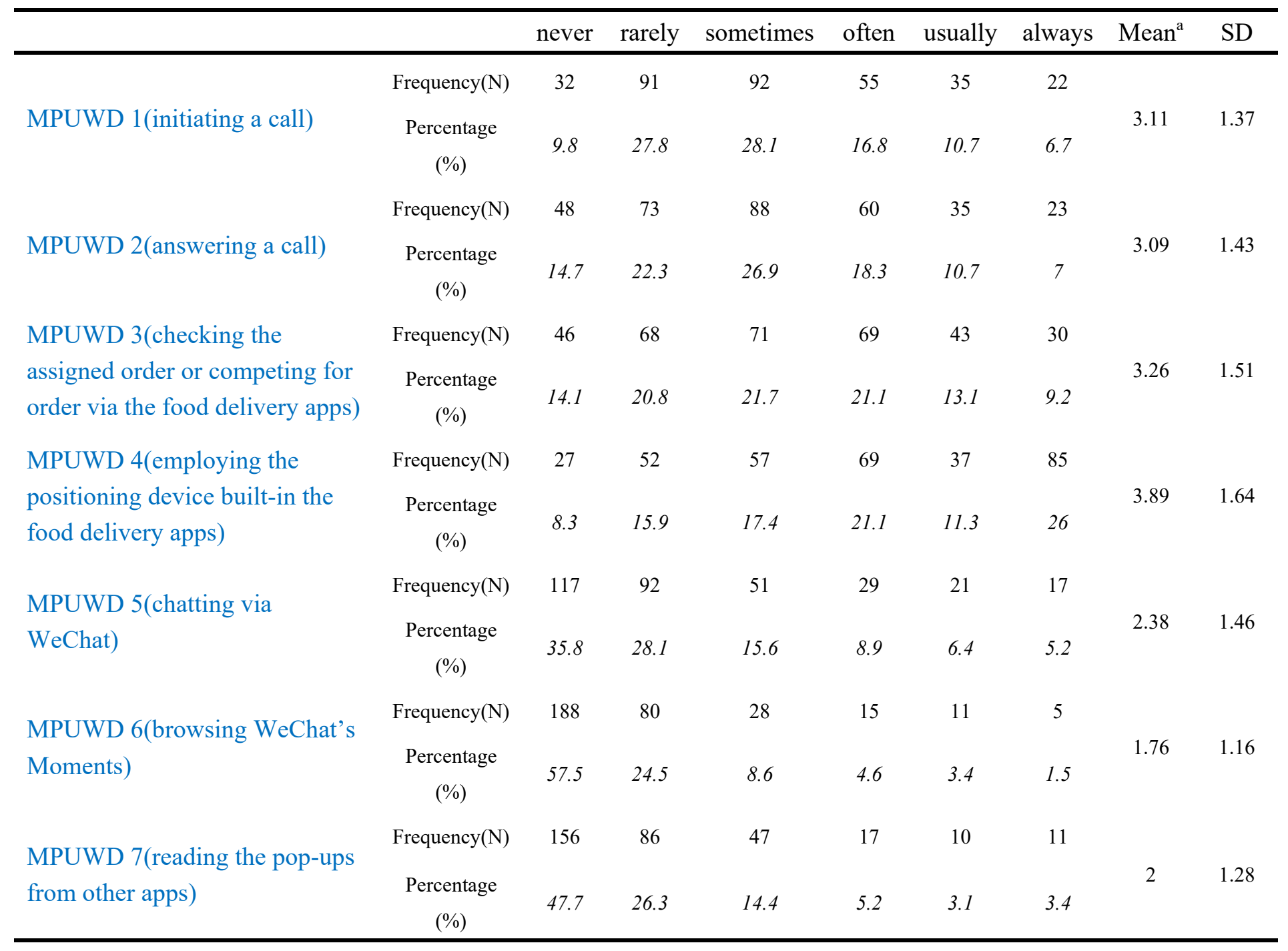

Note: ${ }^{\text {a }}$ Mean where $1=$ never and $6=$ always. 


\section{Structural equation model}

\section{Measurement models}

The three modified instruments including mobile phone use while driving, driving self-efficacy, and MPUWD risk perception were evaluated for convergent and discriminant properties with EFA and CFA. Initially, the measurements models did not exhibit desirable fit statistics using the collected data. Afterwards, model modifications were conducted to trim the theoretical measurement models fit to the data better(Byrne, 2010). More specifically, 2 items for mobile phone use while driving were eliminated, one for its low factor loading, and one for lowing the values of $\chi 2 / \mathrm{df}$ and RMSEA to obtain acceptable thresholds. For MPUWD risk perception, 3 items were removed and an error covariance was added to a pair of items based on modification indices. According to modification indices, 2 and 4 items from each subscale of driving self-efficacy were deleted by iterative testing. The finalized theoretical models were well-fitted to the collected data according to the recommended goodness-of-fit indices (Table 2). Notably, MPUWD risk perception was a unidimensional factor model and the other two were second-ordered factor models.

Table 2 Fit indices of the modified instruments

\begin{tabular}{lcccccc}
\hline Model fit indices & $\begin{array}{l}\chi 2 / \text { df } \\
\text { Reference standard }\end{array}$ & GFI & AGFI & CFI & NFI & RMSEA \\
\cline { 2 - 7 } & $1-3$ & $\geq 0.90$ & $\geq 0.80$ & $\geqslant 0.90$ & $\geqslant 0.90$ & $\leq 0.08$ \\
\hline MPURWD & .398 & .998 & .993 & 1.000 & .998 & .000 \\
MPURWD risk perception & 2.573 & .971 & .938 & .987 & .979 & .069 \\
driving self-efficacy & 2.673 & .960 & .924 & .984 & .975 & .072 \\
\hline
\end{tabular}




\section{Structural model}

The hypothesized structural model embedded with observed and latent constructs was tested with the application of SEM. The initial analysis of the hypothesized model showed the latent specific driving self-efficacy construct contributed to an improper solution given its negative error variance. We remedied this incorrect estimate by reducing it to a small value of 0.001 in accordance with recommendation from F. Chen, Bollen, Paxton, Curran, and Kirby (2001). Afterwards, the performance of the SEM yielded sufficient model fit $(\chi 2 / \mathrm{df}=1.726$, GFI $=.911$, AGFI $=.886$, $\mathrm{CFI}=.967, \mathrm{NFI}=.926, \mathrm{RMSEA}=.047)$. The finalized model $($ Fig.1) depicted adequate fit $(\chi 2 / \mathrm{df}=$ 1.725, GFI $=.909$, AGFI $=.887, \mathrm{CFI}=.966, \mathrm{NFI}=.924, \mathrm{RMSEA}=.047$ ) after deleting the non-significant paths among certain variables. It is important to remind the readers that the standardized $\beta$ weight from the specific driving self-efficacy to driving self-efficacy equals to 1 . Despite being uncommon, standardized coefficients approaching or larger than one do exist (Geiser, Eid, West, Lischetzke, \& Nussbeck, 2012; Vlachos \& Lin, 2014; Wei et al., 2019) and are admissible (Deegan 1978; Jöreskog, 1999).

Figure 1 demonstrates the results of the proposed model. Among the hypothesized predictors (risk perception, three personality traits), only psychoticism had a significant effect on the frequency of MPUWD behaviors $(\beta=0.14, \mathrm{p}<0.05)$. Therefore, we can conclude that H1 and H5 are supported, while $\mathrm{H} 3$ and $\mathrm{H} 4$ are not supported with the findings of the SEM analysis. Furthermore, there was a substantial direct effect from driving self-efficacy on the frequency of MPUWD, represented by the marked size of the standardized coefficient $(\beta=0.54, p<0.001)$. This indicates that the more positive propensity to believe one's driving ability the participant reported, the more interactions to mobile phone while driving the food deliveryman would 
undertake. Psychoticism $(\beta=0.18, \mathrm{p}<0.01)$ and extraversion $(\beta=0.12, \mathrm{p}<0.05)$ were found to have positive and significant effect on driving self-efficacy whereas the effect from risk perception $(\beta=-0.16, \mathrm{p}<0.01)$ was inverse and significant. Most importantly, the significant correlations between hypothesized predictors (risk perception, two personality traits) and driving self-efficacy and between driving self-efficacy and the frequency of MPUWD are the premise for further examining the indirect effects of the driving self-efficacy.

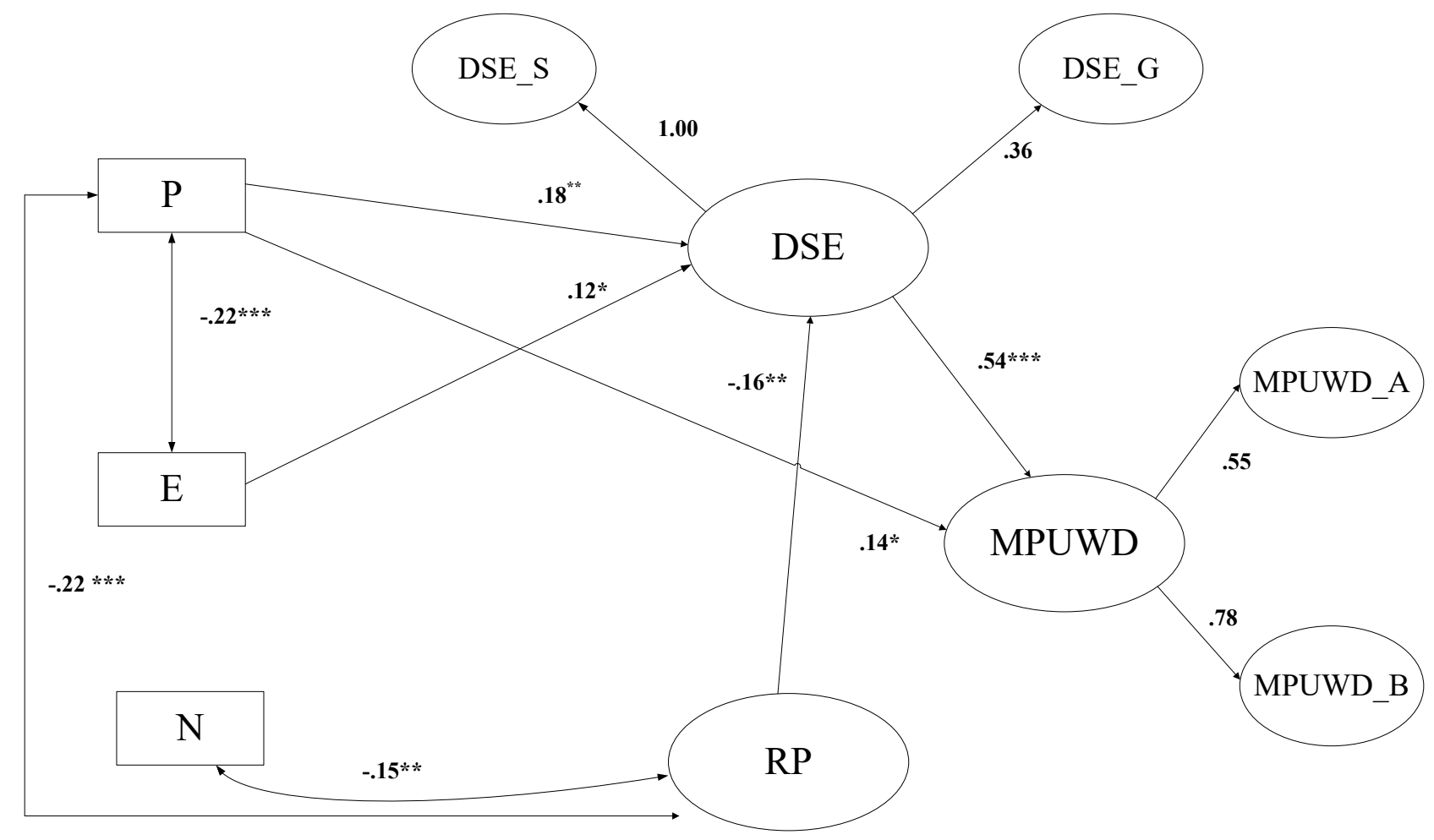

Fig.1. The final structural model with standardized estimates. $* \mathrm{p}<0.05 ; * * \mathrm{p}<0.01 ; * * * \mathrm{p}<0.001$. $\mathrm{DSE}=$ driving self-efficacy, $\mathrm{P}=$ psychoticism, $\mathrm{E}=$ extraversion, $\mathrm{N}=$ Neuroticism, MPUWD=mobile phone use while driving, MPUWD-A and MPUWD-B are the subscales of MPUWD.

\section{Bootstrapping analysis}

Bootstrap procedures in AMOS were applied to estimate the significance of the potential indirect effects with the generation of 2000 bootstrapping samples. The mediation effect of driving 
self-efficacy on the relationship between neuroticism and MPUWD is exempted from the analysis due to neuroticism has no significant impact on driving self-efficacy. The results of the bootstrapping analysis are given in Table 3.

Table3 Direct, indirect, and total effects of the personality traits on MPUWD

\begin{tabular}{|c|c|c|c|c|}
\hline \multirow{2}{*}{\multicolumn{2}{|c|}{ Paths }} & \multirow{2}{*}{ Estimate } & \multicolumn{2}{|c|}{$95 \%$ bias-corrected $(\mathrm{BC})$ Confidence Interval } \\
\hline & & & $\mathrm{p}$ value & $\mathrm{BC}$ \\
\hline \multicolumn{5}{|l|}{ Direct effects } \\
\hline Psychoticism & MPUWD & 0.139 & 0.023 & {$[0.022,0.273]$} \\
\hline Extraversion & MPUWD & -- & & \\
\hline Risk perception & MPUWD & -- & & \\
\hline \multicolumn{5}{|l|}{ Indirect effects } \\
\hline \multicolumn{5}{|c|}{ ( through driving self-efficacy) } \\
\hline Psychoticism & MPUWD & 0.098 & 0.002 & {$[0.041,0.171]$} \\
\hline Extraversion & MPUWD & 0.063 & 0.047 & {$[0.002,0.127]$} \\
\hline Risk perception & MPUWD & -0.086 & 0.015 & {$[-0.166,-0.021]$} \\
\hline \multicolumn{5}{|l|}{ Total effect } \\
\hline Psychoticism & MPUWD & 0.237 & 0.001 & {$[0.101,0.373]$} \\
\hline Extraversion & MPUWD & 0.063 & 0.047 & {$[0.002,0.127]$} \\
\hline Risk perception & MPUWD & -0.086 & 0.015 & {$[-0.166,-0.021]$} \\
\hline
\end{tabular}

As depicted in table 3, the standardized indirect effects of psychoticism $(\beta=0.098, \mathrm{p}<0.01)$, extraversion $(\beta=0.063, \mathrm{p}<0.05)$, and risk perception $(\beta=-0.086, \mathrm{p}<0.05)$ on MPUWD through driving self-efficacy are significant, and there is no inclusion of zero among the three confidential 
intervals. Thus, we can claim that driving self-efficacy mediates the relationships between risk perception, extraversion and psychoticism on one hand and mobile phone use while driving on the other. These findings lend support to all hypotheses with regard to the mediation effects of driving self-efficacy (H2, H6, and H8) but the hypothesis driving self-efficacy acts as a mediating role to the correlation between neuroticism and MPUWD (H7). Considering the only direct effect of psychoticism on MPUWD, it is reasonable to summarize that driving self-efficacy partially mediates the effects of psychoticism on MPUWD, and fully mediates the effects of risk perception and extraversion on MPUWD.

\section{Discussions}

The objectives of the current study were twofold. First, the present study attempted to determine the prevalence of mobile phone use while driving in a professional context, that is, with a sample of food deliveryman in China. A second objective was to explore the influences of personality traits, risk perception on interactions with mobile phone use while driving via driving self-efficacy among this professional group.

To improve our understanding of the mobile phone use on the road in professional contexts, this study assessed the prevalence of seven phone-related distracted driving behaviors among food deliveryman. The descriptive analysis found that $96.3 \%(f=315)$ of food deliveryman reported engaging in at least one of the seven mobile phone behaviors while dispatching food on the wheel. This percentage was higher than other self-reported surveys with samples from general population (Beck, Yan, \& Wang, 2007; Braitman \& McCartt, 2010; Hallett et al., 2011; Hill et al., 2019; Ismeik

et al., 2015; Nurullah et al., 2013; Shi et al., 2016; K. M. White et al., 2010) and from the 
acknowledged heavy adopters - the young adults(Tucker, Pek, Morrish, \& Ruf, 2015). Such a finding is not surprising since food delivery work is highly dependent on using a mobile phone custom app to check orders, get directions to a delivery location, and a mobile phone to talk to customers. Thus, it is fair to argue that mobile phones are frequently used among the sample of food deliveryman we surveyed while driving for their work. As can be seen in Table 1, the mean score of frequency of employing the positioning device built-in the custom apps for cyclists ranks the highest $(\mathrm{M}=3.89)$, which is followed by checking the assigned order or competing for order via the custom apps for cyclists $(M=3.26)$, initiating a call $(M=3.11)$, answering a call $(M=3.09)$, chatting via WeChat $(M=2.38)$, reading the pop-ups from other apps $(M=2.00)$, and browsing WeChat's Moments $(\mathrm{M}=1.76)$. Notably, the disproportionate distribution of the responses pertaining to MPUWD behaviors suggests the deliverymen use their mobile phone on the wheel 'mostly' for business other than for personal purposes. This observation reinforces the previous finding that general road users are prone to engage with their mobile phone for business purpose rather than for personal considerations (Walsh, White, Watson, \& Hyde, 2007), much more so for those spending most of their working hours on the road(Glendon \& Sutton, 2005). However, our study does not provide insightful explanations for the different patterns of MPUWD of professional context exemplified by a recent study(Bruyas \& Evennou, 2018).

Despite the enhanced law enforcements and successive campaigns that try to curb mobile phone use while driving among food deliveryman, engagement with mobile phone while dispatching ordered food remains ubiquitous among this professional group. Given the unsatisfactory outcomes of these interventions, this study further seeks to understand the MPUWD behaviors from socio-psychological perspectives. Our SEM analysis provides evidence of support 
for most hypothesized relationships with regard to how the potential variables affect the self-reported MPUWD behaviors.

With regard to risk perception, this study confirmed the hypothesis (H1) that the perceived risks did not affect MPUWD behaviors, suggesting in spite of recognizing the harmful effect of mobile phone use while driving, the risk perceptions are still not high enough to shape these behaviors. This finding is echoed within some studies in which risk perception dissociate to mobile phone use while driving (Nelson et al., 2009; Walsh et al., 2008) and other risk driving behaviors (Ma, Yan, Huang, \& Abdel-Aty, 2010; Ulleberg \& Rundmo, 2003). There were three theoretical inferences or illustrations for the dissociation between risk perceptions and mobile phone use while driving. First, the respondents continued to engage with their mobile phone while driving because they conceive the psychological, practical, and social benefits surpass the associated dangerous from mobile phone use while driving (Atchley et al., 2011; Nelson et al., 2009; M. P. White, Eiser, \& Harris, 2004). This explanation is similar to what is called the comparative utility, which is used to describe the picture that the reaped benefits exceed the conceived risks from the mobile phone technology (M. P. White, Eiser, Harris, \& Pahl, 2007). Second, it is like that perceived expectations from others to return the calls or reply to messages immediately that may provoke the mobile phone use while driving (Hafetz, Jacobsohn, García-España, Curry, \& Winston, 2010). And lastly, Schlehofer et al. (2010) suggests that it might be those that perceive themselves as equipped with high capabilities to compensate driving distractions that tend to exert more engagements with mobile phone while driving.

Following Schlehofer et al. (2010) suggestion, we proposed that the driving self-efficacy would offset the associated risks from mobile phone use on the wheel, and in turn predict the 
mobile phone use while driving. This hypothesis (H2) was supported by the result of bootstraps analysis of indirect effects that driving self-efficacy fully mediated the relationships between risk perception and MPUWD behaviors. Our finding is in line with a study in which professional drivers committed more unsafe driving behaviors not because they underestimated the associated risks but because of their perceived control over risky situations (Nordfjærn, Jørgensen, \& Rundmo, 2012). Moreover, congruent with previous findings (Ma et al., 2010; Yao \& Wu, 2012), this result verified that risk perception affect unsafe driving behaviors through mediating variables.

A plethora of literature has documented the influences of various personality traits on unsafe driving behaviors in general (Dahlen \& White, 2006; Falco et al., 2013; Guo, Wei, Liao, \& Chu, 2016; Rike et al., 2015) and mobile phone use while driving in particular (Kita \& Luria, 2018; Parr et al., 2016; Sween et al., 2017). However, to date, there is no study relates the personality traits to mobile phone use while driving with samples from professional contexts. To our knowledge, this was the first study to investigate the relationship between the Eysenck personality traits and MPUWD behaviors, and the findings substantiated it was reasonable to generalize linking between personality and unsafe driving behaviors (Ulleberg \& Rundmo, 2003; Q. Zhang, Ge, Qu, Zhang, \& Sun, 2018) from general population to population of professional context with a special focus on to MPUWD behaviors.

In particular, and consistent with previous literature (Furnham \& Saipe, 1993; D.-G. Kim \& Lee, 2017; Tao et al., 2017), psychoticism was found to be positively related to the assessed unsafe driving behaviors, MPUWD behaviors. As Eysenck (Eysenck, 1994) describes, psychoticism reflects the propensity to engage in eccentricity, aggressiveness, novel stimuli and disregard rules and norms. Hence, it is reasonable that people with a psychotic personality tend to commit more 
MPUWD behaviors.

Contrary to our hypothesis, this study found extraversion was not significantly related to MPUWD behaviors. This research finding was supported by existing research in which extraversion showed no effects on aggressive driving (Dahlen, Edwards, Tubré, Zyphur, \& Warren, 2012; H. Zhang, Qu, Ge, Sun, \& Zhang, 2017), drunk driving (Jornet-Gibert, Gallardo-Pujol, Suso, \& Andrés-Pueyo, 2013; MacKenzie, Watling, \& Leal, 2015), distracted driving (Parr et al., 2016; Rozario et al., 2010), and the inclusive risky driving behaviors (Dahlen \& White, 2006). However, there were some other studies suggested that the relationship between extraversion and the targeted unsafe driving behaviors could be positive (Braitman \& Braitman, 2017; Kita \& Luria, 2018; Lansdown, 2012; Sarma, Carey, Kervick, \& Bimpeh, 2013), even passive (Guo et al., 2016; Taubman-Ben-Ari, Mikulincer, \& Gillath, 2004). Likewise, aligning with studies examining the correlations between neuroticism and other risky driving behaviors (Dahlen et al., 2012; Guo et al., 2016; MacKenzie et al., 2015; Sarma et al., 2013), our study found that neuroticism was not significantly correlated to MPUWD behaviors. In contrast, as Q. Zhang et al. (2018) summarized, neuroticism was mainly a predictor of unsafe driving behaviors.

These findings indicate that the effects of extraversion and neuroticism on unsafe driving behaviors are contradictory and inconsistent. There are several possible explanations for the complex results across the above-mentioned studies. First, the inventories employed to gauge the personality traits are not totally consistent. Literature reviews show among the unsafe driving research, International Personality Item Pool (IPIP) (Dahlen \& White, 2006; MacKenzie et al., 2015; Sarma et al., 2013), The Big Five Inventory (Braitman \& Braitman, 2017; H. Zhang et al., 2017), NEO-Five Factor Inventory (NEO-FFI) (Jornet-Gibert et al., 2013; Oltedal \& Rundmo, 2006), 
HEXACO-PI-R (Sween et al., 2017) are used to measure the personality traits, neuroticism and extraversion. Moreover, existing studies investigating the predictive utility of personality traits on unsafe driving have elicited responses from diverse samples (Jovanović, Lipovac, Stanojević, \& Stanojević, 2011; Oltedal \& Rundmo, 2006), which bring challenges to the generalization of the results. Finally, there are diverse practices in the inclusion of control variables, such as age, gender, into the statistical analysis (Dahlen \& White, 2006; Lajunen, 2001).

In relation to the Hypothesis 6, 7, and 8, our research findings depicted that driving self-efficacy was a robust predictor in the relationship between psychoticism and extraversion, and MPUWD behaviors. To be specific, driving self-efficacy worked as a partial mediator on the correlation of psychoticism and MPUWD behaviors, and acted as a full mediator on the effect of extraversion on MPUWD behaviors. Although this is the first study to examine the mediating role of driving self-efficacy on the relationship between personality traits and mobile phone use while driving, the findings of the present study were evidenced by some relevant studies. More closely, similar to the driving self-efficacy used in current study, a study identified biased self-efficacy perceptions mediated the effects of sensation seeking on drunk driving (González-Iglesias et al., 2014). Additionally, some studies provided evidence that there were some other predispositional attitudes towards driving behaviors, including traffic safety climate (Q. Zhang et al., 2018), attitudes toward safe driving (Lucidi, Mallia, Lazuras, \& Violani, 2014; Ulleberg \& Rundmo, 2003), and angering driving (Jovanović et al., 2011), mediated the effects of certain personality traits on unsafe driving behaviors.

Furthermore, the predictive utility of driving self-efficacy on the effects of two personality attributes(psychoticism and extraversion) on MPUWD behaviors is underpinned by our result that 
driving self-efficacy shows great explanatory power on MPUWD behaviors, which is in line with the previous findings that beliefs or confidences in driving capacities when performing certain behaviors (McLernon, 2014; Rike et al., 2015; Tronsmoen, 2010) and perceived behavior control positively contributed to the unsafe driving behaviors (Castanier, Deroche, \& Woodman, 2013; Horswill \& McKenna, 1999).

These findings generate some theoretical and practical implications. For the theoretical insights, the present study replicated the linking between personality traits and unsafe driving behaviors, and developed the personality_driving self-efficacy_MPUWD behaviors model with the data from food deliveryman. Additionally, this study explored the influencing mechanism of risk perception on MPUWD behaviors by introducing driving self-efficacy, and empirically verified the previous theoretical inference that risk perception may indirectly lead to the mobile phone use behaviors on the wheel (Przepiorka et al., 2018). At the practical level, we first should acknowledge personality traits are of importance in identifying those who often use the mobile phone while driving, and to target at-risk food deliveryman for training to not undertake phone relevant distractions. Afterwards, we recommend taking the driving self-efficacy into account when develop intervention programs and educational campaigns. Considering driving self-efficacy working as a mediating variable in our theoretical model and significantly predicting the MPUWD behaviors, intervention efforts should be tailored to simulate food deliveryman at most to objectively appraise their abilities to interact to mobile phone while driving for food dispatching and to undermine optimism bias alike those spending most of their working hours on the road (Dalziel \& Job, 1997; Stavrinos et al., 2016), if necessary.

Nevertheless, some limitations of this study should be considered. First, it is recognized that 
the participants might have underreported their mobile phone use behaviors on wheel due to the social desirability bias. Second, this study employed responses of food deliveryman from solely two municipalities (Nanjing and Xuzhou) with convenience sampling, results from which perhaps not be generalizable to food cyclists elsewhere. Third, the inventories with risk perception and driving self-efficacy used in this study were tailored from the ones developed under non-Chinese cultures, which to some extent cannot desirably reflect the counterparts from Chinese food cyclists. There are concerns about the common methods bias pertaining to the construct driving self-efficacy. Fourth, this study examines the cross-sectional data, which generally cannot be used to infer the causality. Fifth, imputing missing values using mean and median method may result in biased estimates. We also acknowledge that the MPUWD scale included a mixture of work-related and non-work-related behaviors (e.g., answering a phone call could be either work or personal). Therefore, future research could examine difference in MPUWDs according to either personal or work-related usage. And finally, prior studies have showed that social, personal and legal norms are crucial factors in shaping mobile phone use while driving (Bayer \& Campbell, 2012; H.-S. Kim, 2018; Waddell \& Wiener, 2014; Walsh et al., 2008), more attention should be paid to this direction for future research.

\section{Conclusions}

The boosting food delivery industry in China is rightly catering for people's lifestyle. However, it also generates the unintended effects to road safety, resulting from the food deliveryman's illegal driving, and interactions to mobile phone while dispatching foods on e-bikes in particular. To our knowledge, this is the first study to focus on the MPUWD behaviors among food deliveryman by contributing to the literature in terms of the extent and potential determinants that this professional 
group makes use of mobile phone while on work-related travels. One of the contributions of this study is the confirmation of the prevalence of MPUWD behaviors among food deliveryman. In general, the heterogeneous distribution of the assessed MPUWD behavior suggests that food deliveryman interact to mobile phone while on work-related travels mostly for business rather than entertainment. Secondly, the SEM estimates show that among the hypothesized predictors, only psychoticism directly relate to the MPUWD behaviors, suggesting that personality traits and perceived risk perception per se display limited predicting utility to MPUWD behaviors among food deliveryman. And the bootstrap estimates indicate that driving self-efficacy and the proposed predictors together well illustrate the assessed exogenous variables with driving self-efficacy completely mediate the relationship between risk perception and MPUWD behaviors, and the relationship between extraversion and MPUWD behaviors, as well as partially mediate the link between psychoticism and MPUWD behaviors. These findings imply that developing and implementing intervention efforts in a concerted way would curb these behaviors effectively.

\section{Declaration of interest}

Declarations of interest: none

\section{Funding}

This study is supported by China University of Mining and Technology's funding on World-Class Universities and Disciplines Special Projects (No.2018WHCC02), The National Social Science Fund of China (No. 17CZZ021). 


\section{Acknowledgements}

The authors would like to acknowledge Hui Zhang and Shimin Chen for answering our questions, and

Pan for his assistance in data analysis. The authors acknowledge Wen Qing, Ting Chen, Ying Zhang,

Rui Zhang, Zi Ju, Weiwei Wang, Xiaorong $\mathrm{Xu}$, and Xingxing $\mathrm{Xu}$ for their assistance with data collection in heating summer days.

\section{References}

Ajzen, I. (1991). The theory of planned behavior. Organizational behavior and human decision processes, 50(2), 179-211.

Albuquerque, I., de Lima, M. P., Matos, M., \& Figueiredo, C. (2013). The interplay among levels of personality: The mediator effect of personal projects between the Big Five and subjective well-being. Journal of Happiness Studies, 14(1), 235-250.

Armitage, C. J., \& Conner, M. (2001). Efficacy of the theory of planned behaviour: A meta - analytic review. British Journal of Social Psychology, 40(4), 471-499.

Atchley, P., Atwood, S., \& Boulton, A. (2011). The choice to text and drive in younger drivers: Behavior may shape attitude. Accident Analysis

Prevention, 43(1), 134-142.

Bandura, A. (1997). Self-efficacy: The exercise of control. New York: Freeman.

Bayer, J. B., \& Campbell, S. W. (2012). Texting while driving on automatic: Considering the frequency-independent side of habit. Computers in Human Behavior, 28(6), 2083-2090.

Beck, K. H., Yan, F., \& Wang, M. Q. (2007). Cell phone users, reported crash risk, unsafe driving behaviors and dispositions: A survey of motorists in Maryland. Journal of safety research, 38(6), 683-688.

Bellinger, D. B., Budde, B. M., Machida, M., Richardson, G. B., \& Berg, W. P. (2009). The effect of cellular telephone conversation and music listening on response time in braking. Transportation Research Part F: Traffic Psychology and Behaviour, 12(6), 441-451.

Bianchi, A., \& Phillips, J. G. (2005). Psychological predictors of problem mobile phone use. CyberPsychology \& Behavior, 8(1), 39-51.

Braitman, K. A., \& Braitman, A. L. (2017). Patterns of distracted driving behaviors among young adult drivers: Exploring relationships with personality variables. Transportation research part F: traffic sychology

behaviour, 46, 169-176.

Braitman, K. A., \& McCartt, A. T. (2010). National reported patterns of driver cell phone use in the United States. Traffic injury prevention, 11(6), 543-548.

Briggs, G. F., Hole, G. J., \& Land, M. F. (2011). Emotionally involving telephone conversations lead to driver error and visual tunnelling. Transportation research part F: traffic psychology

behaviour, 14(4), 313-323.

Brown, P. M., George, A. M., \& Rickwood, D. (2019). Perceived risk and anticipated regret as factors predicting 
intentions to text while driving among young adults. Transportation Research Part F: Traffic sychology, 62.

Brusque, C., \& Alauzet, A. (2008). Analysis of the individual factors affecting mobile phone use while driving in France: Socio-demographic characteristics, car and phone use in professional and private contexts. Accident Analysis Prevention, 40(1), 35-44.

Bruyas, M.-P., \& Evennou, M. (2018). Phone use and motives of professional drivers: a focus group approach. Paper presented at the 6th International Conference on Driver Distraction and Inattention.

Butt, S., \& Phillips, J. G. (2008). Personality and self reported mobile phone use. Computers in Human Behavior, 24(2), 346-360.

Byrne, B. M. (2010). Structural equation modeling with AMOS: basic concepts, applications, and programming (2nd ed.). New York, NY: Routledge.

Castanier, C., Deroche, T., \& Woodman, T. (2013). Theory of planned behaviour and road violations: The moderating influence of perceived behavioural control. Transportation research part F: traffic sychology

behaviour, 18, 148-158.

Cellular News. (2019). Countries That Ban Cell Phones While Driving. Retrieved from https://cellularnews.com/news/archive/car-ban/

Chen, F., Bollen, K. A., Paxton, P., Curran, P. J., \& Kirby, J. B. (2001). Improper solutions in structural equation models: Causes, consequences, and strategies. Sociological methods

research, 29(4), 468-508.

Chen, H.-Y. W., \& Donmez, B. (2016). What drives technology-based distractions? A structural equation model on social-psychological factors of technology-based driver distraction engagement. Accident Analysis \& Prevention, 91, 166-174.

Choudhary, P., \& Velaga, N. R. (2017). Modelling driver distraction effects due to mobile phone use on reaction time. Transportation Research Part C: Emerging Technologies, 77, 351-365.

Claveria, J. B. (2018). Evaluating Distracted Driving Behavior Among Drivers of Large Trucks Through Econometric Modelling: A Pacific Northwest Case Study. (Master thesis), Oregon State University,

CNNIC. (2019). 43th Statistical report on the development of China Internet network. Retrieved from http://www.cnnic.cn/gywm/xwzx/rdxw/20172017 7056/201902/W020190228474508417254.pdf

Dahlen, E. R., Edwards, B. D., Tubré, T., Zyphur, M. J., \& Warren, C. R. (2012). Taking a look behind the wheel: An investigation into the personality predictors of aggressive driving. Accident Analysis and Prevention, 45, 1-9.

Dahlen, E. R., \& White, R. P. (2006). The Big Five factors, sensation seeking, and driving anger in the prediction of unsafe driving. Personality and Individual Differences, 41(5), 903-915.

Dalziel, J. R., \& Job, R. S. (1997). Motor vehicle accidents, fatigue and optimism bias in taxi drivers. Accident Analysis \& Prevention, 29(4), 489-494.

Deegan , J. (1978). On the occurrence of standardized regression coefficients greater than one. Educational and Psychological Measurement, 38(4), 873-888.

Drews, F. A., Pasupathi, M., \& Strayer, D. L. (2008). Passenger and cell phone conversations in simulated driving. Journal of experimental psychology: Applied, 14(4), 392.

Economist, T. (2017). China's food-delivery business is booming. So is waste.

Elvik, R. (2011). Effects of mobile phone use on accident risk: Problems of meta-analysis when studies are few and bad. Transportation Research Record: Journal of the Transportation Research Board(2236), 20-26.

Eysenck, H. J. (1994). Personality: Biological foundations. In P. A. Vernon (Ed.), The neuropsychology

of individual differences. London: Academic Press.

Falco, A., Piccirelli, A., Girardi, D., Dal Corso, L., \& Nicola, A. (2013). Risky riding behavior on two wheels: The role of cognitive, social, and personality variables among young adolescents. Journal of safety research, 46, 47-57. 
Furnham, A., \& Saipe, J. (1993). Personality correlates of convicted drivers. Personality and individual differences, 14(2), 329-336.

Gaskin, J. (2017). Data screening. Gaskination's StatWiki. Retrieved from http://statwiki.kolobkreations.com/index.php?title=Data_screening

Gauld, C. S., Lewis, I., \& White, K. M. (2014). Concealing their communication: Exploring psychosocial predictors of young drivers' intentions and engagement in concealed texting. Accident Analysis Prevention, 62, 285-293.

Gauld, C. S., Lewis, I., White, K. M., Fleiter, J. J., \& Watson, B. (2017). Smartphone use while driving: What factors predict young drivers' intentions to initiate, read, and respond to social interactive technology? Computers in Human Behavior, 76, 174-183.

Geiser, C., Eid, M., West, S. G., Lischetzke, T., \& Nussbeck, F. W. (2012). A comparison of method effects in two confirmatory factor models for structurally different methods. Structural Equation Modeling: A Multidisciplinary Journal, 19(3), 409-436.

George, S., Clark, M., \& Crotty, M. (2007). Development of the Adelaide driving self-efficacy scale. Clinical Rehabilitation, 21(1), 56-61.

Glendon, A. I., \& Sutton, D. (2005). Observing motorway driving violations. In D. A. H. D. L. Wiesenthal (Ed.), Contemporary issues in road user behavior traffic safety. New York: Nova Science Publishers.

Gloss, M., McGregor, M. \& Brown, B. (2016, May). Designing for labour: Uber and the on-demand mobile workforce. In Proceedings of the $2016 \mathrm{CHI}$ conference on human factors in computing systems (pp. 1632-1643). ACM.

González-Iglesias, B., Gómez-Fraguela, J. A., \& Luengo, M. Á. (2014). Sensation seeking and drunk driving: The mediational role of social norms and self-efficacy. Accident Analysis

Prevention, 71, 22-28.

Groeger, J. A., \& Rothengatter, J. A. (1998). Traffic psychology and behaviour. Transportation research part F: traffic psychology

behaviour, 1(1), 1-9.

Group, I. R. (2017). 2017-2018 China Online Takeout Market Research Report. Retrieved from http://www.iimedia.cn/60449.html

Guo, M., Wei, W., Liao, G., \& Chu, F. (2016). The impact of personality on driving safety among Chinese high-speed railway drivers. Accident Analysis \& Prevention, 92, 9-14.

Hafetz, J. S., Jacobsohn, L. S., García-España, J. F., Curry, A. E., \& Winston, F. K. (2010). Adolescent drivers' perceptions of the advantages and disadvantages of abstention from in-vehicle cell phone use. Accident Analysis and Prevention, 42(6), 1570-1576.

Hair, J., Black, W., Babin, B., \& Anderson, R. (2014). Multivariate Data Analysis (Seventh ed.). Harlow: Pearson Education Limited.

Hallett, C., Lambert, A., \& Regan, M. A. (2011). Cell phone conversing while driving in New Zealand: Prevalence, risk perception and legislation. Accident Analysis

Prevention, 43(3), 862-869.

Haque, M. M., \& Washington, S. (2014). A parametric duration model of the reaction times of drivers distracted by mobile phone conversations. Accident Analysis \& Prevention, 62, 42-53.

Hayashi, Y., Rivera, E. A., Modico, J. G., Foreman, A. M., \& Wirth, O. (2017). Texting while driving, executive function, and impulsivity in college students. Accident Analysis \& Prevention

$102,72-80$.

He, J., McCarley, J. S., \& Kramer, A. F. (2014). Lane keeping under cognitive load: performance changes and mechanisms. Human factors, 56(2), 414-426. 
Hill, T., Sullman, M., \& Stephens, A. (2019). Mobile phone involvement, beliefs, and texting while driving in Ukraine. Accident Analysis \& Prevention, 125, 124-131.

Horswill, M. S., \& McKenna, F. P. (1999). The Effect of Perceived Control on Risk Taking. Journal of Applied Social Psychology, 29(2), 377-391.

Hu, L. t., \& Bentler, P. M. (1999). Cutoff criteria for fit indexes in covariance structure analysis: Conventional criteria versus new alternatives. Structural equation modeling: a multidisciplinary journal, 6(1), 1-55.

Ige, J., Banstola, A., \& Pilkington, P. (2016). Mobile phone use while driving: Underestimation of a global threat. Journal of Transport \& Health, 3(1), 4-8.

Ismeik, M., Al-Kaisy, A., \& Al-Ansari, K. (2015). Perceived risk of phoning while driving: A case study from Jordan. Safety science, 78, 1-10.

Jinjiang Economist. (2018). 9 food deliverymen caught for their engagement in mobile phone activities while driving. Retrieved from http://www.sohu.com/a/232940343229636

Jöreskog, K. G. (1999). How large can a standardized coefficient be. Retrieved from http://www.statmodel.com/download/Joreskog.pdf

Jornet-Gibert, M., Gallardo-Pujol, D., Suso, C., \& Andrés-Pueyo, A. (2013). Attitudes do matter: The role of attitudes and personality in DUI offenders. Accident Analysis \& Prevention, 50, 445-450.

Jovanović, D., Lipovac, K., Stanojević, P., \& Stanojević, D. (2011). The effects of personality traits on driving-related anger and aggressive behaviour in traffic among Serbian drivers. Transportation research part F: traffic psychology

behaviour, 14(1), 43-53.

Kim, D.-G., \& Lee, Y. (2017). Identifying the influences of demographic characteristics and personality of inveterate drunk drivers on the likelihood of driving under the influence of alcohol (DUIA) recurrence. International Journal of Urban Sciences, 21(3), 300-311.

Kim, H.-S. (2018). The role of legal and moral norms to regulate the behavior of texting while driving. Transportation research part F: traffic psychology

behaviour

52, 21-31.

Kim, S., Mone, M. A., \& Kim, S. (2008). Relationships among self-efficacy, pay-for-performance perceptions, and pay satisfaction: A Korean examination. Human Performance, 21(2), 158-179.

Kita, E., \& Luria, G. (2018). The mediating role of smartphone addiction on the relationship between personality and young drivers' smartphone use while driving. Transportation research part F: traffic psychology

behaviour, 59, 203-211.

Kline, R. B. (2011). Principles and practice of structural equation modeling, (3rd ed.). New York: The Guilford Press.

Laberge-Nadeau, C., Maag, U., Bellavance, F., Lapierre, S. D., Desjardins, D., Messier, S., \& Saïdi, A. (2003). Wireless telephones and the risk of road crashes. Accident Analysis \& Prevention, 35(5), 649-660.

Lajunen, T. (2001). Personality and accident liability: are extraversion, neuroticism and psychoticism related to traffic and occupational fatalities? Personality and individual differences, 31(8), 1365-1373.

Lansdown, T. C. (2012). Individual differences and propensity to engage with in-vehicle distractions-A self-report survey. Transportation research part F: traffic psychology

behaviour, 15(1), 1-8.

Lee, J. D., Young, K. L., \& Regan, M. A. (2008). Defining driver distraction. In J. D. L. M.A. Regan, and K.I. \& K. L. Young (Eds.), Driver distraction: theory, effects and

mitigation (Vol. 13, pp. 31-40). Boca Raton, FL: CRC Press.

Lesch, M. F., \& Hancock, P. A. (2004). Driving performance during concurrent cell-phone use: are drivers aware of their 
performance decrements? Accident Analysis

Prevention, 36(3), 471-480.

Lipovac, K., Đerić, M., Tešić, M., Andrić, Z., \& Marić, B. (2017). Mobile phone use while driving-literary review. Transportation Research Part F: Traffic Psychology and Behaviour, 47, 132-142.

Lucidi, F., Mallia, L., Lazuras, L., \& Violani, C. (2014). Personality and attitudes as predictors of risky driving among older drivers. Accident Analysis \& Prevention, 72, 318-324.

Ma, M., Yan, X., Huang, H., \& Abdel-Aty, M. (2010). Safety of public transportation occupational drivers: Risk perception, attitudes, and driving behavior. Transportation Research Record, 2145(1), 72-79.

MacKenzie, J. E., Watling, C. N., \& Leal, N. L. (2015). What aspects of demographic, personality, attitudes and perceptions of law enforcement influence self-reported likelihood of drink driving? Journal of Risk Research, 18(9), 1203-1219.

Maij-de Meij, A. M., Kelderman, H., \& van der Flier, H. (2008). Fitting a mixture item response theory model to personality questionnaire data: Characterizing latent classes and investigating possibilities for improving prediction. Applied Psychological Measurement, 32(8), 611-631.

Malhotra, N., Charlton, S., Starkey, N., \& Masters, R. (2018). Driving speed choice: the role of conscious monitoring and control (reinvestment) when driving. Transportation research part F: traffic psychology

behaviour, 57, 115-128.

Mallia, L., Lazuras, L., Violani, C., \& Lucidi, F. (2015). Crash risk and aberrant driving behaviors among bus drivers: the role of personality and attitudes towards traffic safety. Accident Analysis

Prevention, 79, 145-151.

McCartt, A. T., \& Geary, L. L. (2004). Longer term effects of New York State's law on drivers' handheld cell phone use. Injury prevention, 10(1), 11-15.

McCartt, A. T., Hellinga, L. A., Strouse, L. M., \& Farmer, C. M. (2010). Long-term effects of handheld cell phone laws on driver handheld cell phone use. Traffic injury prevention, 11(2), 133-141.

McEvoy, S. P., Stevenson, M. R., \& Woodward, M. (2006). Phone use and crashes while driving: a representative survey of drivers in two Australian states. Medical journal of Australia, 185(11-12), 630-634.

McLernon, M. Y. (2014). Risk Propensity, Self-Efficacy and Driving Behaviors Among Rural, Off-Duty Emergency Services Personnel. (PhD), Southern Illinois University Carbondale,

McNally, B., \& Bradley, G. L. (2014a). Driving construals: Personal Construct Theory in a reckless driving context. Transportation research part F: traffic psychology

behaviour, 24, 71-82.

McNally, B., \& Bradley, G. L. (2014b). Re-conceptualising the reckless driving behaviour of young drivers. Accident Analysis

Prevention, 70, 245-257.

Mirman, J. H., Durbin, D. R., Lee, Y.-C., \& Seifert, S. J. (2017). Adolescent and adult drivers' mobile phone use while driving with different interlocutors. Accident Analysis

Prevention, 104, 18-23.

Mohamed, M., \& Bromfield, N. F. (2017). Attitudes, driving behavior, and accident involvement among young male drivers in Saudi Arabia. Transportation research part F: traffic psychology

behaviour, 47, 59-71.

Nelson, E., Atchley, P., \& Little, T. D. (2009). The effects of perception of risk and importance of answering and initiating a cellular phone call while driving. Accident Analysis

Prevention, 41(3), 438-444.

Nemme, H. E., \& White, K. M. (2010). Texting while driving: Psychosocial influences on young people's texting 
intentions and behaviour. Accident Analysis

Prevention, 42(4), 1257-1265.

Nordfjærn, T., Jørgensen, S. H., \& Rundmo, T. (2012). Safety attitudes, behaviour, anxiety and perceived control among professional and non-professional drivers. Journal of Risk Research, 15(8), 875-896.

Nurullah, A. S., Thomas, J., \& Vakilian, F. (2013). The prevalence of cell phone use while driving in a Canadian province. Transportation research part F: traffic psychology

behaviour, 19, 52-62.

Oltedal, S., \& Rundmo, T. (2006). The effects of personality and gender on risky driving behaviour and accident involvement. Safety science, 44(7), 621-628.

Parr, M. N., Ross, L. A., McManus, B., Bishop, H. J., Wittig, S. M., \& Stavrinos, D. (2016). Differential impact of personality traits on distracted driving behaviors in teens and older adults. Accident Analysis

Prevention

92, 107-112.

Przepiorka, A. M., Błachnio, A. P., \& Sullman, M. J. (2018). Factors influencing intentions to text while driving among Polish drivers. Transportation research part F: traffic psychology

behaviour, 55, 306-313.

Qian, M., Wu, G., Zhu, R., \& Zhang, S. (2000). Development of the revised Eysenck personality questionnaire short scale for Chinese (EPQ-RSC). Acta Psychologica Sinica, 32(03), 317-323.

Rakauskas, M. E., Gugerty, L. J., \& Ward, N. (2004). Effects of naturalistic cell phone conversations on driving performance. Journal of safety research, 35(4), 453-464.

Redelmeier, D. A., \& Tibshirani, R. (1997). Association between cellular-telephone calls and motor vehicle collisions. New England Journal of Medicine, 336(7), 453-458.

Regan, M. A., Hallett, C., \& Gordon, C. P. (2011). Driver distraction and driver inattention: Definition, relationship and taxonomy. Accident Analysis

Prevention, 43(5), 1771-1781.

Renner, W., \& Anderle, F.-G. (2000). Venturesomeness and extraversion as correlates of juvenile drivers' traffic violations. Accident Analysis \& Prevention, 32(5), 673-678.

Rike, P.-O., Johansen, H. J., Ulleberg, P., Lundqvist, A., \& Schanke, A.-K. (2015). Exploring associations between self-reported executive functions, impulsive personality traits, driving self-efficacy, and functional abilities in driver behaviour after brain injury. Transportation research part F: traffic psychology

behaviour, 29, 34-47.

Rozario, M., Lewis, I., \& White, K. M. (2010). An examination of the factors that influence drivers' willingness to use hand-held mobile phones. Transportation research part F: traffic psychology

behaviour, 13(6), 365-376.

Rupp, M. A., Gentzler, M. D., \& Smither, J. A. (2016). Driving under the influence of distraction: examining dissociations between risk perception and engagement in distracted driving. Accident Analysis

Prevention, 97, 220-230.

Sarma, K. M., Carey, R. N., Kervick, A. A., \& Bimpeh, Y. (2013). Psychological factors associated with indices of risky, reckless and cautious driving in a national sample of drivers in the Republic of Ireland. Accident Analysis

Prevention, 50, 1226-1235.

Schlehofer, M. M., Thompson, S. C., Ting, S., Ostermann, S., Nierman, A., \& Skenderian, J. (2010). Psychological predictors of college students' cell phone use while driving. Accident Analysis

Prevention, 42(4), 1107-1112.

Seo, D.-C., \& Torabi, M. R. (2004). The impact of in-vehicle cell-phone use on accidents or near-accidents among college 
students. Journal of American College Health, 53(3), 101-108.

Shepherd, C. (2017). Speed over safety? China's food delivery industry warned

over

accidents.

Retrieved

from

https://uk.reuters.com/article/uk-china-delivery-accidents-insight/speed-over-safety-chinas-food-delivery-ind ustry-warned-over-accidents-idUKKC

Shi, J., Xiao, Y., \& Atchley, P. (2016). Analysis of factors affecting drivers' choice to engage with a mobile phone while driving in Beijing. Transportation research part F: traffic psychology

behaviour, 37, 1-9.

Simmons, S. M., Hicks, A., \& Caird, J. K. (2016). Safety-critical event risk associated with cell phone tasks as measured in naturalistic driving studies: A systematic review and meta-analysis. Accident Analysis \& Prevention, 87, 161-169.

Stavrinos, D., Heaton, K., Welburn, S. C., McManus, B., Griffin, R., \& Fine, P. R. (2016). Commercial truck driver health and safety: exploring distracted driving performance and self-reported driving skill. Workplace Health \& Safety, 64(8), 369-376.

Strayer, D. L., Drews, F. A., \& Johnston, W. A. (2003). Cell phone-induced failures of visual attention during simulated driving. Journal of experimental psychology: Applied, 9(1), 23.

Struckman-Johnson, C., Gaster, S., Struckman-Johnson, D., Johnson, M., \& May-Shinagle, G. (2015). Gender differences in psychosocial predictors of texting while driving. Accident Analysis Prevention, 74, 218-228.

Sullman, M., Hill, T., \& Stephens, A. (2018). Predicting intentions to text and call while driving using the theory of planned behaviour. Transportation Research Part F: Traffic sychology

Behaviour, 58, 405-413.

Sullman, M. J., Przepiorka, A. M., Prat, F., \& Blachnio, A. P. (2018). The role of beliefs in the use of hands-free and handheld mobile phones while driving. Journal of Transport

Health, 9, 187-194.

Sundström, A. (2008). Construct validation and psychometric evaluation of the self-efficacy scale for driver competence. European Journal of Psychological Assessment, 24(3), 198-206.

Sween, M., Ceschi, A., Tommasi, F., Sartori, R., \& Weller, J. (2017). Who is a Distracted Driver? Associations between Mobile Phone Use while Driving, Domain - Specific Risk Taking, and Personality. Risk analysis, 37(11), 2119-2131.

Talaat, S., \& Yuan, Y. (2017). Migrant Food-Delivery Workers Struggle to Belong in Beijing.

Tao, D., Zhang, R., \& Qu, X. (2017). The role of personality traits and driving experience in self-reported risky driving behaviors and accident risk among Chinese drivers. Accident Analysis

Prevention

99, 228-235.

Taubman-Ben-Ari, O., Mikulincer, M., \& Gillath, O. (2004). The multidimensional driving style inventory-scale construct and validation. Accident Analysis \& Prevention, 36(3), 323-332.

Taubman-Ben-Ari, O., Mikulincer, M., \& Iram, A. (2004). A multi-factorial framework for understanding reckless driving-appraisal indicators and perceived environmental determinants. Transportation Research Part F: Traffic Psychology

Behaviour, 7(6), 333-349.

Tian, Y., \& Robinson, J. D. (2017). Predictors of cell phone use in distracted driving: extending the theory of planned behavior. Health communication, 32(9), 1066-1075.

Törnros, J. E., \& Bolling, A. K. (2005). Mobile phone use-effects of handheld and handsfree phones on driving performance. Accident Analysis Prevention, 37(5), 902-909. 
Troglauer, T., Hels, T., \& Christens, P. F. (2006). Extent and variations in mobile phone use among drivers of heavy vehicles in Denmark. Accident Analysis \& Prevention, 38(1), 105-111.

Tronsmoen, T. (2008). Associations between self-assessment of driving ability, driver training and crash involvement among young drivers. Transportation Research Part F: Traffic Psychology

Behaviour, 11(5), 334-346.

Tronsmoen, T. (2010). Associations between driver training, determinants of risky driving behaviour and crash involvement. Safety science, 48(1), 35-45.

Tucker, S., Pek, S., Morrish, J., \& Ruf, M. (2015). Prevalence of texting while driving and other risky driving behaviors among young people in Ontario, Canada: Evidence from 2012 and 2014. Accident Analysis \& Prevention, 84, 144-152.

Ulleberg, P., \& Rundmo, T. (2003). Personality, attitudes and risk perception as predictors of risky driving behaviour among young drivers. Safety science, 41(5), 427-443.

Vlachos, I., \& Lin, Z. (2014). Drivers of airline loyalty: Evidence from the business travelers in China. Transportation Research Part E: Logistics

Transportation Review, 71, 1-17.

Waddell, L. P., \& Wiener, K. K. (2014). What's driving illegal mobile phone use? Psychosocial influences on drivers' intentions to use hand-held mobile phones. Transportation research part F: traffic sychology, 22, 1-11.

Walsh, S. P., White, K. M., Hyde, M. K., \& Watson, B. (2008). Dialling and driving: Factors influencing intentions to use a mobile phone while driving. Accident Analysis Prevention, 40(6), 1893-1900.

Walsh, S. P., White, K. M., Watson, B. C., \& Hyde, M. K. (2007). Psychosocial factors influencing mobile phone use while driving. Retrieved from

Wang, R. (2019, January 1st, 2019). Food deliverymen violated traffic regulations twice are asked to participant special education campaigns. Modern Retrieved from http://dz.xdkb.net/page/1/2019-01/09/A14/20190109A14 pdf.pdf

Wei, J., Pomerantz, E. M., Ng, F. F.-Y., Yu, Y., Wang, M., \& Wang, Q. (2019). Why does parents' involvement in youth's learning vary across elementary, middle, and high school? Contemporary Educational Psychology, 56, $262-274$.

Weller, J. A., Shackleford, C., Dieckmann, N., \& Slovic, P. (2013). Possession attachment predicts cell phone use while driving. Health psychology, 32(4), 379.

White, K. M., Hyde, M. K., Walsh, S. P., \& Watson, B. (2010). Mobile phone use while driving: An investigation of the beliefs influencing drivers' hands-free and hand-held mobile phone use. Transportation Research Part F: Traffic sychology

Behaviour, 13(1), 9-20.

White, M. P., Eiser, J. R., \& Harris, P. R. (2004). Risk perceptions of mobile phone use while driving. Risk Analysis: An International Journal, 24(2), 323-334.

White, M. P., Eiser, J. R., Harris, P. R., \& Pahl, S. (2007). Who reaps the benefits, who bears the risks? Comparative optimism, comparative utility, and regulatory preferences for mobile phone technology. Risk Analysis: An International Journal, 27(3), 741-753.

WHO. (2011). Mobile phone use: a growing problem of driver distraction. (6051499008).

Wilson, F. A., \& Stimpson, J. P. (2010). Trends in fatalities from distracted driving in the United States, 1999 to 2008. American journal of public health, 100(11), 2213-2219.

Wohleber, R. W., \& Matthews, G. (2016). Multiple facets of overconfidence: Implications for driving safety. Transportation research part F: traffic psychology

behaviour, 43, 265-278.

Xinhua News Agency. (2017). How does the $\mathrm{O} 2 \mathrm{O}$ food delivery industry affect your life? Retrieved from 
http://m.xinhuanet.com/food/2017-12/21/c 1122144280.htm

Yao, L., \& Wu, C. (2012). Traffic safety for electric bike riders in China: attitudes, risk perception, and aberrant riding behaviors. Transportation research record, 2314(1), 49-56.

Zhang, H., Qu, W., Ge, Y., Sun, X., \& Zhang, K. (2017). Effect of personality traits, age and sex on aggressive driving: Psychometric adaptation of the Driver Aggression Indicators Scale in China. Accident Analysis \& Prevention, 103, 29-36.

Zhang, Q., Ge, Y., Qu, W., Zhang, K., \& Sun, X. (2018). The traffic climate in China: The mediating effect of traffic safety climate between personality and dangerous driving behavior. Accident Analysis \& Prevention, 113, 213-223.

Zhou, R., Wu, C., Rau, P.-L. P., \& Zhang, W. (2009). Young driving learners' intention to use a handheld or hands-free mobile phone when driving. Transportation Research Part F: Traffic Psychology and Behaviour, 12(3), 208-217.

Zhou, V. (2018). The tough, daring drivers behind China's food delivery craze. Inkstone. Retrieved from https://www.inkstonenews.com/society/dangerous-job-driving-chinas-33-billion-food-delivery-industry/articl $\underline{\mathrm{e} / 2144165}$ 